\title{
Uma história da Comunidade AURORa NARRAda POR SEUS SUJEITOS LOCAIS: TRADIÇÃO, CULTURA E EDUCAÇÃO DO CAMPO
}

\author{
A AURORA COMMUNITY HISTORY NARRATED BY ITS LOCAL SUBJECTS: \\ TRADITION, CULTURE AND RURAL EDUCATION
}

DOI: 10.23926/RPD.2526-2149.2020.v5.n2.p1512-1528.id781

\section{Marilza Rodrigues da Silva \\ Licencianda em Educação do Campo (UFTM) \\ rodriguesmarilza039@gmail. $\underline{\text { com }}$}

\section{Vaniclésia Soares}

\section{Alves}

Licencianda em Educação do Campo (UFTM)

vaniclesiasoaresalves@gmail .com

\section{Wederlando}

Geronimo de Souza

Licenciando em Educação do Campo (UFTM)

wederlandorpm@hotmail.co $\underline{\mathrm{m}}$

\section{Fernando Luís Pereira Fernandes}

Doutor em Educação

(UFSCar)

Professor na Universidade

Federal do Triângulo

Mineiro (UFTM)

fernando.fernandes@uftm.ed u.br
Resumo: Este artigo tem como objetivo socializar resultados de um trabalho acadêmico produzido no âmbito de duas disciplinas de um curso de Licenciatura em Educação do Campo, com proposta de um estudo de natureza histórica, visando à (re)constituição da história de uma comunidade rural, nas vozes dos sujeitos locais. Para isso, contou-se com o referencial teórico-metodológico da História Oral e com a realização de entrevistas semiestruturadas com dois moradores da Comunidade Aurora, município de Rio Pardo de Minas-MG. Buscou-se constituir uma versão da história da Comunidade, remontando aos seus primeiros moradores para poder compreender, em suas narrativas, os aspectos pertinentes à cultura, religião e educação daquele território. Como resultado, percebeu-se que a Comunidade Aurora, apesar de não ser reconhecida como sendo tradicional, salienta características peculiares quanto ao modo de ser e viver no campo, com implicações importantes na formação de futuros professores em Educação do Campo.

Palavras-chave: História Oral. Comunidade Tradicional. Licenciatura em Educação do Campo. Regime de Alternância. Tempo-Comunidade.

\begin{abstract}
This paper socializes the findings of academic work produced within the scope of two subjects of the Rural Education Undergraduate Course, with the study proposal of a historical nature, aiming at the history (re)constitution of a rural community, in the voices of local subjects. It relied on the theoretical-methodological framework of Oral History and the realization of semi-structured interviews with two residents of the Aurora Community, Rio Pardo de Minas city, MG. It sought to constitute a history version of the Community, going back to its first residents to be able to understand, in their narratives, the relevant aspects to the culture, religion and education of that territory. As findings, it was realized that the Community, despite not being recognized as being traditional, highlights peculiar characteristics regarding the way of being and living in the countryside, with implications for the Initial Teacher Training in Rural Education.

Keywords: Oral History. Traditional Community. Rural Education Undergraduate Course. Alternation Regime. Community-Time.
\end{abstract}




\title{
1 INTRODUÇÃO
}

Este artigo tem como objetivo socializar os resultados de um trabalho acadêmico produzido pelos três primeiros autores nas disciplinas Seminário Integrador I e Espaços Comunitários, Territórios e Integração de Saberes I (ECTIS I), do curso de Licenciatura em Educação do Campo - LECampo -, da Universidade Federal do Triângulo Mineiro - UFTM, estudo este orientado pelo quarto autor do artigo e docente do referido curso. Esclarece-se que o quarto autor foi responsável pela disciplina Seminário Integrador I e compartilhou a disciplina ECTIS I com mais três professores, além de supervisionar a produção acadêmica dos três licenciandos, demais autores do artigo.

Esse exercício acadêmico consistiu na produção de um estudo cujo enfoque seria o resgate da história das comunidades rurais de origem dos licenciandos, mediante a realização de entrevistas semiestruturadas com seus moradores.

Ambas as disciplinas são oferecidas no primeiro período do curso. A disciplina Seminário Integrador I, de caráter prático, com carga horária de 30 horas-aula desenvolvida em Tempo-Escola, teve como conteúdo programático: Educação Rural e Educação do Campo, Comunidade, Território e História Oral (como referencial teórico-metodológico nos estudos na área de Educação). Já a disciplina ECTIS I, cuja carga horária é de 60 horas-aula - destina 10 horas-aula delas para o período intensivo de estudos na universidade e 50 horas-aula para as atividades em Tempo-Comunidade -, possui a seguinte ementa:

\begin{abstract}
A docência no/do campo articulada com a gestão de processos educativos comunitários. Pedagogia da alternância. Territórios, saberes e reconhecimento de identidades do campo. Trabalho no/do campo. Integração dos conteúdos específicos das áreas de conhecimento aos desafios concretos das comunidades do campo por meio de propostas de intervenção, pesquisa e extensão (UFTM, 2019, p. 99).
\end{abstract}

Dessa forma, as discussões e estudos inclusos em Seminário Integrador I subsidiaram o trabalho acadêmico nas comunidades de origem dos licenciandos e, consequentemente, o desenvolvimento da carga horária de ECTIS I.

Os três futuros professores em Educação do Campo residem no município de Rio Pardo de Minas, localizado no norte do estado de Minas Gerais, com uma população, em sua maioria, residente na zona rural, em alguma das mais de 100 comunidades dessa área. Essa região é conhecida por Gerais, compreendida na fronteira entre os biomas do Cerrado e da Caatinga; peculiarmente, parte de seus moradores se reconhece e é reconhecida como geraizeiro, o qual se constitui histórica, política e culturalmente nesse território. De maneira geral, essa população 
tem o seu modo de produção associado ao extrativismo de frutos do cerrado, flores e plantas medicinais e a solta de animais em regiões de chapada, além da agricultura de subsistência.

Mesmo com a breve descrição sobre as práticas produtivas articuladas pelo geraizeiro, vê-se necessário conceituar, neste artigo, o que se entende por comunidade. Quando se consulta um dicionário, verifica-se a polissemia desse termo. No dicionário on-line Michaelis ${ }^{1}$, apresentam-se dez sentidos para a palavra comunidade, sendo alguns deles explicitados e brevemente discutidos. Um primeiro sentido, mais simples e próximo do senso comum é "qualidade ou estado daquilo que é comum a diversos indivíduos", o qual explora o sentido do radical comum. Outro sentido a ser destacado remete à ideia de território ou às relações estabelecidas entre as pessoas que ali vivem e convivem: "População que vive em determinado local ou região, ligada por interesses comuns".

Brandão e Borges (2014) detalham uma conceituação de comunidade que amplia os sentidos obtidos no dicionário:

\begin{abstract}
(...) comunidade é o lugar humano da vida. Desde tempos antigos foi e segue sendo o lugar social arrancado da natureza, ou nela encravado ainda, em que pessoas, famílias e redes de parentes e "comuneiros" reúnem-se para viver suas vidas e dar, entre palavras e gestos, um sentido a ela. Em termos modernos, a comunidade é o lugar da escolha. É a associação - quanto mais livre e autoassumida melhor - de pessoas que se congregam para serem, em meio a um mundo como o da grande cidade, o que desejam ser nela, ou por oposição a ela (BRANDÃO; BORGES, 2014, p. 2).
\end{abstract}

Além dessa definição, Brandão e Borges (2014) distinguem quatro tipos de comunidade: comunidade primitiva, comunidade tradicional, comunidade de exclusão e comunidade de adesão. Destacam-se, no presente artigo, algumas características de comunidade tradicional (CRUZ, 2012): a relação com a natureza (ou racionalidade ambiental); a relação com o território e a territorialidade; a racionalidade econômico-produtiva; as inter-relações com os outros grupos e da região e a autoidentificação.

Para além de vínculos firmados entre as pessoas e o seu território, o sentido de pertencimento dos moradores com a terra também se fortalece com a cultura, a identidade e a

\footnotetext{
1 Disponível em: https://michaelis.uol.com.br/moderno-portugues/busca/portugues-brasileiro/comunidade. Acesso em: 19 jun. 2020. Verbetes: 1 Qualidade ou estado daquilo que é comum a diversos indivíduos. 2 Grupo de pessoas que vivem em comum e cujos recursos materiais pertencem a todos. 3 Conjunto de pessoas que vivem numa mesma região, com o mesmo governo, e que partilham as mesmas tradições históricas e/ou culturais. $4 \mathrm{~A}$ sociedade como um todo. 5 SOCIOL População que vive em determinado local ou região, ligada por interesses comuns. 6 POR EXT Esse local ou essa região. 7 Qualquer conjunto de indivíduos ligados por interesses comuns (culturais, econômicos, políticos, religiosos etc.) que se associam com frequência ou vivem em conjunto. 8 Grupo de pessoas com características comuns, inseridas numa sociedade maior que não compartilha de suas características básicas; sociedade. 9 Grupo de pessoas ligadas pela mesma profissão ou atividade. 10 Conjunto de indivíduos (animais ou vegetais) que vivem juntos na mesma área e que, em geral, interagem ou dependem uns dos outros para existir; biocenose.
} 
constituição de um sistema de símbolos e significados para as atividades com sentido próprio para aquele grupo, fortemente arraigado aos seus modos de vida (BRANDÃO; BORGES, 2014).

Como moradores de comunidades rurais, os três primeiros autores perceberam a importância de buscar conhecer, compreender e resgatar a história de constituição da comunidade, de evidenciar os aspectos culturais e religiosos e, não menos importante, o processo de escolarização em seus territórios. Mas, a história oficial quase não tem dados sobre esses aspectos, de modo a explicitar o processo de organização dessas comunidades.

Tratando desse último aspecto - o processo de escolarização -, especialmente, sabe-se que as populações do campo sempre foram relegadas a segundo plano no que tange à educação, seja pela ausência ou precária infraestrutura adequada ou de prédios escolares, mobiliário, recursos didáticos e materiais pedagógicos, seja pela falta de professores com formação em Magistério e/ou em nível superior, ou ainda, como acontece, pela adesão a um modelo de ensino baseado no paradigma urbano (ARROYO, 2007) e alheio aos saberes e modos de vida no campo no âmbito escolar, características do modelo de Educação Rural (RIBEIRO, 2012).

$\mathrm{Na}$ seção seguinte, serão abordados os aspectos metodológicos do trabalho em questão bem como o contexto de produção de dados.

\section{Metodologia e Contexto}

Para a realização do trabalho da disciplina, apoiou-se em referencial teóricometodológico da História Oral, entendendo que essa perspectiva de produção de conhecimento possibilita registrar uma história narrada de baixo para cima, colocando em protagonismo aqueles indivíduos que são invisíveis aos olhos da sociedade e que não participam da construção da denominada história oficial, no caso, povos de comunidades rurais da região norte do estado de Minas Gerais.

Concorda-se com Ichikawa e Santos (2003) que a história oral "é uma história do tempo presente, pois implica uma percepção do passado como algo que tem continuidade hoje e cujo processo histórico não está acabado" (ICHIKAWA; SANTOS, 2003, p. 2). A prática utilizada no resgate da história da Comunidade Aurora permitiu aos licenciandos, autores do artigo, se aproximarem da prática de um historiador oral, de maneira que pudessem inquirir pelo passado de sua comunidade e, ao mesmo tempo, por suas identidades (LOZANO, 2006).

Como instrumento de produção de dados, valeu-se de entrevistas semiestruturadas, as quais foram audiogravadas por meio de smartphone e transcritas posteriormente. A etapa 
seguinte foi a de selecionar trechos das falas dos entrevistados com base nos eixos analíticos definidos a priori: aspectos relativos à fundação e primeiros moradores da Comunidade, à produção econômica, manifestações culturais e religiosas e o processo de escolarização de seus moradores.

A justificativa para a escolha dessa comunidade para o trabalho está no fato de que as duas primeiras autoras são moradoras da Comunidade Aurora. O terceiro autor, apesar de não residir na mesma comunidade, também é oriundo de comunidade rural do mesmo município e identifica a dinâmica de seu lugar de origem como semelhante a da Comunidade Aurora.

Localizada a 32 quilômetros do município de Rio Pardo de Minas, a Comunidade Aurora conta com, aproximadamente, 80 famílias, as quais vivem da produção de farinha e polvilho e da agricultura de subsistência.

Para a construção desse percurso de constituição da Comunidade Aurora - em relação aos aspectos históricos de sua fundação, religiosos, culturais e educacionais -, foram entrevistados dois moradores, Roberto e Cláudio² .

Na seção seguinte, apresentam-se a análise dos dados e reflexões sobre a história da Comunidade Aurora.

\section{ANÁliSE e REFLEXões}

Para iniciar, destaca-se um breve perfil de cada um dos entrevistados. Roberto tem 46 anos, casado, tem dois filhos e vive na Comunidade Aurora desde que nasceu. Ele é filho de um dos fundadores da Comunidade e, na época da entrevista, era presidente da Associação de Moradores. Justifica-se a sua escolha por ele ter muito conhecimento sobre a história da Comunidade e pela função que ocupava.

Cláudio tem 45 anos, casado, tem duas filhas e vive desde sempre na Comunidade. Na época da realização da entrevista, ele fazia parte da Associação dos Produtores Rurais da comunidade. Ele foi escolhido para participar do trabalho por também conhecer a história da comunidade, pelas memórias contadas por seus pais, e pelo seu engajamento em diferentes atividades e eventos organizados na comunidade.

A Comunidade Aurora, segundo narram os entrevistados, teria recebido esse nome em virtude de uma mulher chamada Aurora, a qual teria sido a primeira moradora da Comunidade:

Pesquisador: Por que o nome Aurora?

\footnotetext{
${ }^{2}$ Por questões éticas, optou-se por utilizar nomes fictícios para os entrevistados. 
Roberto: Aqui na Aurora... foi o seguinte. A Comunidade de Aurora, ela foi nascida é... conhecida por uma mulher que chamava Aurora, na época que morava, né... na região. E aí, por devido ela morar na região e por ela ser a primeira pessoa a morar aqui, aí a comunidade ficou conhecida como Aurora. Só que depois dessa mulher chamada Aurora, vem uma mulher que chamava Judite, que... fazia as pessoas escravas, judiava dos negros... Que, na época que eles (os escravos) construíram muitas cerca de pedra, construíram muros lá que se pode ver... E aí, a comunidade foi crescendo né. Através disso aí, ela levou o nome de Aurora, ela veio crescendo, né e tornando novas pessoas.

Em seu depoimento, Roberto não consegue situar a época que Aurora teria chegado à região em que se localiza a Comunidade que recebeu o nome dela. Porém, destaca-se em sua fala uma mulher chamada Judite, a qual, segundo Roberto, maltratava as pessoas e escravizava negros, dando-lhes como tarefas, por exemplo, a construção de muros de pedra, com o objetivo de evitar a circulação de animais e a entrada de pessoas estranhas no território. Por citar que houve a escravização de pessoas na região, parece que a constituição da comunidade teria ocorrido no final do século XIX, quando houve a abolição da escravatura, ou início do século XX. Brito (2013) explicita que a região norte de Minas Gerais teria sido povoada, não só por grupos indígenas que habitaram a região antes da chegada dos colonizadores, mas por negros que fugiram de diferentes regiões do Brasil. Pelo depoimento de Roberto, portanto, também pode ter havido escravos negros na região.

Um dos indícios indicados por Roberto, uma cerca de pedra construída pelos escravos, ainda está em pé na Comunidade, conforme se vê na figura seguinte:

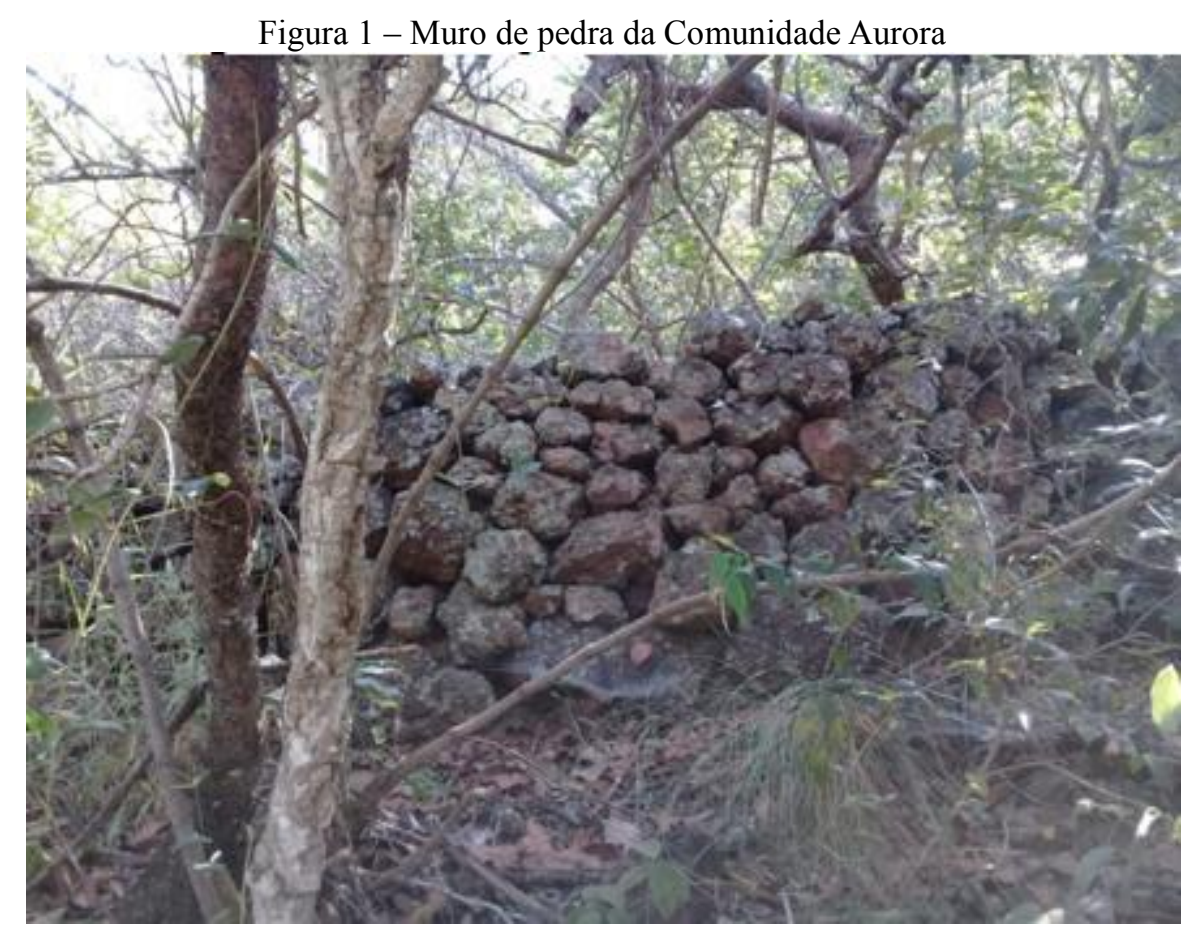

Fonte: Arquivo dos autores 
Cláudio complementa algumas informações sobre Aurora com a afirmativa de que seus pais a conheceram:

Pesquisador: Há quantos anos o senhor reside na comunidade?

Cláudio: Ué... Eu nasci aqui e sempre fui criado aqui, sempre morei aqui.

Pesquisador: O senhor conheceu a primeira moradora da comunidade?

Cláudio: Não, mas meus pais conheceram. É... falava que era uma mulher muito pra frente, sabia de tudo. Isso foi na década de 60 , onde os meus pais ainda era criança.

Pesquisador: Então, ela que mandava na comunidade?

Cláudio: É... todos obedecia ela, tudo que ela falava era certo.

Pesquisador: Foi ela que deu o nome à comunidade?

Cláudio: Foi, pois ela foi a primeira moradora da comunidade.

Pesquisador: Onde ela morou ainda existe alguém que mora no local onde ela viveu?

Cláudio: Sim, neste mesmo local sou eu com a minha família que residimos, meus avós compraram o terreno e foi passado de herança.

As informações disponibilizadas por Cláudio complementam as informações do depoimento de Roberto, no que se refere à época em que Aurora teria chegado àquelas terras. Como os pais de Cláudio tinham 74 e 76 anos na época da entrevista, eles eram, pois, crianças na década de 1950. Possivelmente, Aurora teria nascido na segunda metade do século XIX. Ou seja, se tomar como referência a chegada de Aurora na região como um marco de origem da Comunidade, esta teria, no mínimo, 130 anos. No local em que Cláudio vive com a sua família ainda se encontra um muro erguido pelos escravos, construído com argila:

Figura 2- Muro de argila construído pelos escravos na Comunidade Aurora

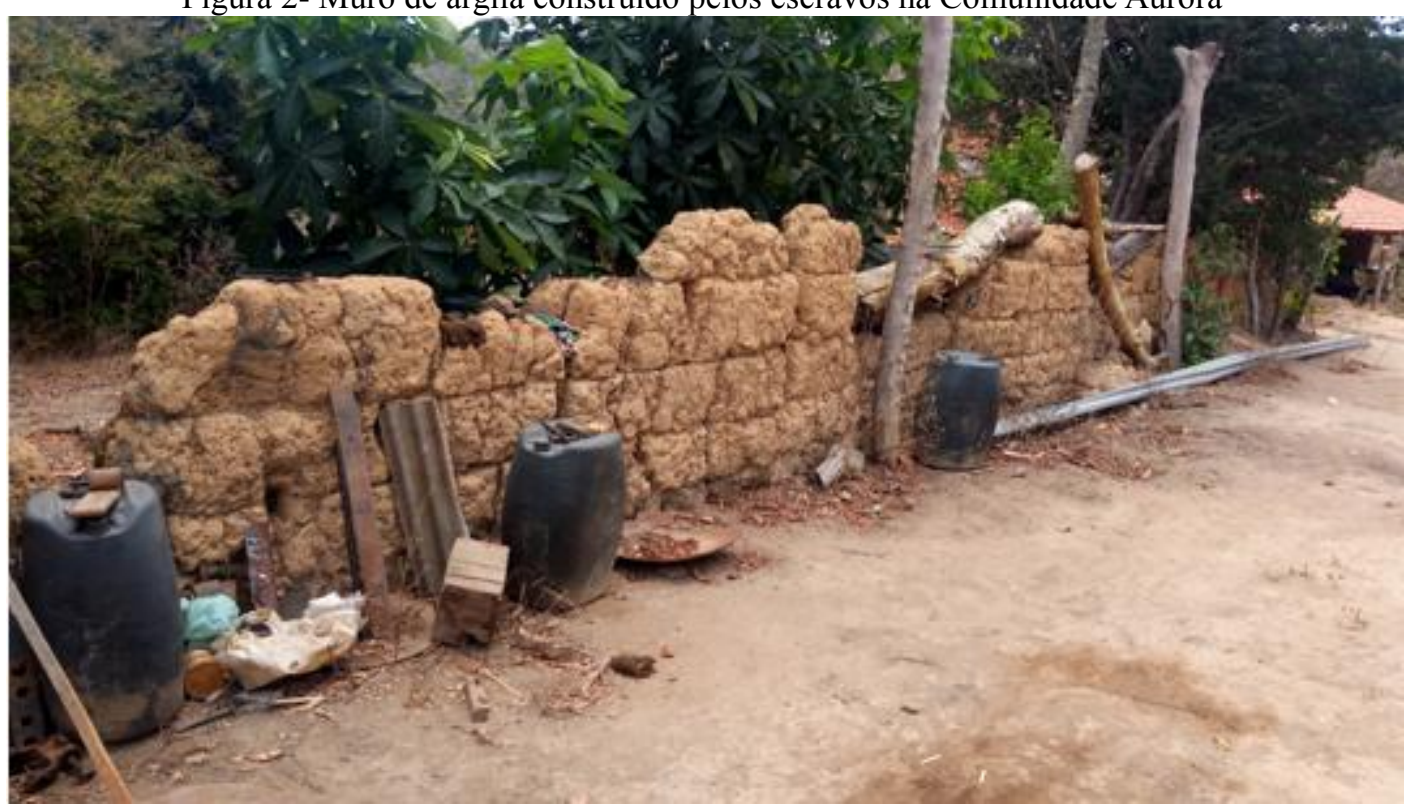

Fonte: Arquivo dos autores 
Em face do exposto anteriormente, há indícios de que a Comunidade Aurora teria sofrido influências da população negra, a qual teria chegado à região nos tempos do Brasil Colonial, e as evidências para tal, além das falas de Roberto e Cláudio, são os resquícios do muro de argila e da cerca de pedra. Para um maior aprofundamento do tema, seria necessária a busca por outros depoimentos e documentos, além da exigência de tempo para empreender a investigação.

Outra questão a ser problematizada nas entrevistas era sobre o trabalho e o modo de produção praticados pelos moradores da Comunidade:

Pesquisador: Qual meio de trabalho as pessoas de antigamente costumavam utilizar?

Roberto: As pessoas viviam plantando arroz e... fazendo horta. Às vezes, nós, homens, trabalhava alugado, trabalhava de enxada pras pessoas. Uns fazia farinha, num sofrimento, porque eram aqueles forninhos que torrava a farinha no braço. Era muito difícil, tinha vez que ficava até de madrugada mexendo na tenda.

O modo de produção agrícola da Comunidade era baseado na agricultura de subsistência, com a produção de vegetais para o próprio consumo e o plantio de mandioca para a produção de farinha. Roberto explica que, para a obtenção de alguma outra renda, muitos homens trabalhavam alugado, trabalhava de enxada pras pessoas, ou seja, fazendeiros chamavam moradores das proximidades para trabalhar em suas propriedades durante o dia, na capina e na limpeza de suas plantações e, ao finalizar o dia, recebiam o valor em dinheiro pelo serviço prestado. Nos dias atuais, é comum o deslocamento de pessoas da Comunidade, inclusive famílias inteiras, para outras regiões para trabalhar na safra. A maioria delas se muda no meio do ano para o sul de Minas Gerais (região de São Sebastião do Paraíso) e nordeste do estado de São Paulo (região de Franca) na colheita do café ${ }^{3}$.

Roberto também destaca o uso do forninho para a torragem de farinha, que exigia maior sacrifício físico daqueles que a faziam. Era preciso que duas pessoas se incumbissem da tarefa, cada uma de um lado, com um pequeno rodo de madeira na mão, levando a farinha de um lado para o outro. Atividades produtivas manejadas de maneira artesanal são características da produção agrícola familiar, mesmo que conte, atualmente, com a energia elétrica em alguma etapa de produção.

\footnotetext{
${ }^{3}$ É uma realidade em diferentes comunidades rurais do município de Rio Pardo de Minas, em virtude das escassas oportunidades de trabalho.
} 
Figura 3 - Forno de antigamente que se usava para a produção de farinha
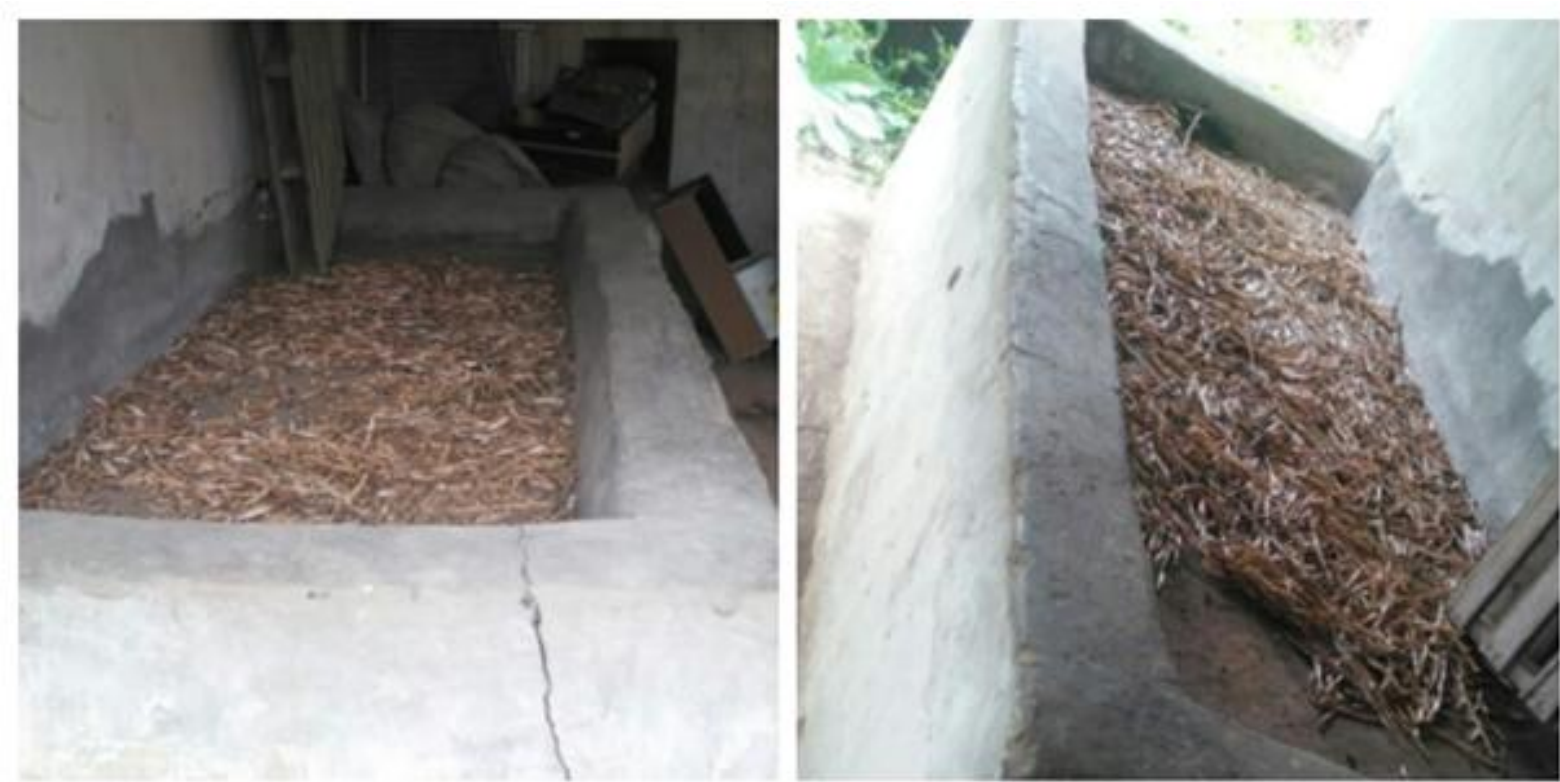

Fonte: Nilza Santos ${ }^{4}$

Antigamente, era preciso contar com toda a família para a feita da farinha. Nos dias atuais, com a chegada da eletricidade na Comunidade no ano de 2001, a torragem de farinha é feita com forno elétrico, demandando somente uma pessoa para colocar a farinha e controlar o calor para que não deixe passar do ponto. A prensa, onde se enxuga a massa de mandioca ralada, não é elétrica, mas o seu manuseio é bem mais simples.

A produção agrícola e as atividades econômicas associadas a ela descritas anteriormente denotam o que Cruz (2012) denomina como racionalidade econômico-produtiva, em que o trabalho é realizado por toda a família ou por grupos de pessoas com vínculos parentais, cujas atividades estão, de maneira geral, associadas à pesca, à caça, à agricultura de subsistência e, em menor quantidade, ao artesanato e à arte. $\mathrm{O}$ autor ainda cita o uso da tecnologia e a divisão do trabalho na realização das atividades econômicas pelas comunidades:

A tecnologia utilizada por essas comunidades na intervenção no meio ambiente é relativamente simples, de baixo impacto nos ecossistemas. Há reduzida divisão técnica e social do trabalho, sobressaindo o modelo artesanal de produção, no qual o produtor e sua família dominam todo o processo de produção até o produto final (CRUZ, 2012, p. 596).

Prioriza-se a produção para subsistência e parte dela também é destinada a diferentes práticas sociais organizadas, como procissões e festas religiosas. $\mathrm{Na}$ existência de excedente, este é comercializado para que as famílias adquiram produtos industrializados (CRUZ, 2012).

\footnotetext{
${ }^{4}$ Moradora da Comunidade Aurora. 
Roberto afirma que a organização do território e das poucas famílias que ali viviam, com o objetivo de constituir uma Comunidade, começou, de fato, com a chegada de outras famílias, por volta do início dos anos de 1970; e algumas atividades da Comunidade encontramse hoje consolidadas, como aquelas ligadas à religião e ao futebol, este último como opção de lazer:

Roberto: É... na época não tinha... Não tinha celebração, as coisas que as pessoas usavam [fazer] eram Folia de Reis e rezava o Terço... E aí por diante né. E foi assim. Tinha também campo de futebol, as pessoas brincavam de futebol na época, e sempre o maior encontro das pessoas era na casa dos amigos, fazia sempre farra na casa dos amigos e assim foi crescendo. Até que um dia, já uns...isso já tem uns 40 anos que decidiu formar uma comunidade que, no qual formou com três pessoas: meu pai, seu Geraldo, seu Vicente e seu Osdite.

Mesmo com a existência de um pequeno grupo de famílias, ainda não havia sido constituída, oficialmente, a Comunidade Aurora. A ocorrência da Folia de Reis e a reza do Terço - manifestações da Igreja Católica - podem ser considerados importantes elos construídos entre as pessoas que viviam no território antes de sua fundação oficial, desde a articulação dos três moradores citados por Roberto. Em outros termos, já havia laços entre os moradores, culturais e religiosos, os quais davam sentido às suas vidas por meio de gestos e palavras (BRANDÃO; BORGES, 2014), caracterizando-os como pertencentes a uma mesma comunidade. As reuniões religiosas, quando não aconteciam na casa de algum morador, eram organizadas sob a sombra de grandes árvores ou, até mesmo, no cemitério da Comunidade.

A primeira igreja foi construída na Comunidade no ano de 1980 por iniciativa dos seus moradores, mas, bem antes, já havia comemorações de ordem religiosa em suas residências: a Folia de Reis, as festas juninas, as lapinhas ${ }^{5}$, entre outras. Para conseguirem edificar a primeira igreja, os moradores promoviam eventos no cemitério, como leilão, barraquinhas, bingo e outras atrações. Com o passar dos anos, depois da construção da primeira igreja, houve o aumento do número de fiéis, resultando na construção de uma igreja maior, a qual foi inaugurada no dia 24 de junho de 2015, dia de São João Batista, padroeiro da Comunidade.

Ainda acerca da dimensão religiosa e cultural presente na Comunidade, a Festa de Reis e a Festa Junina resistem aos tempos atuais: não se sabe ao certo desde quando há a manifestação da Folia de Reis, porém, moradores mais velhos contam que ela teve início já com os primeiros moradores da Comunidade. Aurora, por ser uma comunidade do campo e por ter

\footnotetext{
${ }^{5}$ A lapinha é um presépio convencional, composto por flores e imagens de santos. A maioria das pessoas da Comunidade costuma fazê-la para pagar promessas e/ou por costume. Ela é montada no dia 24 de dezembro, com cantos aos Santos Reis e a reza do Santo Terço. No dia 6 de janeiro, data em que se desmonta a lapinha, a cerimônia transcorre da mesma forma.
} 
o privilégio de ainda ter a Folia de Reis, se esforça em manter viva essa tradição, pois a sua manutenção é uma forma de manter a história viva, iniciada pelos antepassados, é um modo de engajar os jovens na continuidade da Folia, já que o grupo é formado por pessoas idosas. Esse reconhecimento também vem de comunidades vizinhas, as quais convidam a Folia de Aurora a comparecer em seus eventos em diferentes períodos do ano.

Compreende-se que, se não houver esse movimento de engajamento da juventude da Comunidade, pode ocorrer o mesmo que se passou em comunidades vizinhas: a extinção das Folias de Reis e, com isso, a perda de parte significativa da história, cultura e identidade da Comunidade. Além da Folia de Reis, outras festas religiosas são organizadas e realizadas:

Pesquisador: Quais são as festas e as culturas realizadas na Comunidade?

Roberto: Bom, aqui na comunidade a gente tem várias tradições... tem a festa do padroeiro no mês de junho, que é uma festa que nós festejamos e homenageia São João Batista. Fazemos fogueira, Folia de Reis, catiras, às vezes [tem] quadrilha... é... E aqui na comunidade, o mês mais movimentado é o mês de junho, porque muitas famílias faz fogueira, levanta bandeira... faz Folia de Reis em suas casas. É o modo de festejarmos aqui.

Roberto cita diferentes ações próprias do período junino, as quais geralmente não estão associadas à festa de São João Batista. A Catira, por exemplo, é uma dança típica do sertão brasileiro e que também se manifesta culturalmente na Comunidade. Outro exemplo é a Folia de Reis, que é convidada por muitas famílias nas levantadas de bandeira, fazendo-se presente no mês de janeiro e durante as festas juninas.

Observa-se como a festa de São João Batista, acompanhada de outras manifestações culturais e religiosas, é um evento constituinte da identidade dos moradores da Comunidade Aurora, quando Roberto finaliza a sua fala: "É o modo de festejarmos aqui". Para Brandão e Borges (2014), as diferentes práticas sociais realizadas em determinado território podem se constituir em um "calendário-cartografia de práticas, de celebrações, de marcações culturais do passar do tempo, entre trabalho e festa, que, em boa medida demarca também os tempos pessoal e coletivamente culturais com que uma identidade do "ser daqui" se constrói e se modifica" (BRANDÃO; BORGES, 2014, p. 18-19, aspas dos autores).

Cláudio, assim como Roberto, descreve como é organizada a Festa Junina em Aurora, e explica o sentido do Roubo da Bandeira:

Pesquisador: Na comunidade, tem festas culturais?

Cláudio: Sim, nessa igreja da nossa comunidade acontece uma festa de São João Batista, que tem a tradição da Bandeira Roubada. Esta festa acontece no mês de junho e realizada do dia 15 ao dia 23. É uma festa que todos da comunidade ajudam para realizar. Nós convidamos outras comunidades vizinhas para festejar com nós estes nove dias de festa. No último dia da festa, os ladrões trazem a bandeira de volta e 
entrega para ser levantada novamente. Nesse dia tem cantoria de Reis, comidas típicas do mês de junho... e a metade desta festa é feita pelos ladrões da bandeira. Este tipo de festa que acontece é a tradicional festa junina. Não acontece só na igreja, as pessoas também fazem nas suas casas. Mas, algumas são mais diferentes porque não tem a levantada da bandeira, eles opina (preferem) fazer a festa e o tradicional forró que todos da comunidade gosta e que vai a noite toda.

Um ponto a salientar da fala de Cláudio é a respeito do Roubo da Bandeira. Essa é uma brincadeira antiga praticada no período junino e que estava esquecida, mas que, aos poucos, vem se tornando um dos aspectos fundamentais das festas da Comunidade. Funciona assim: o morador hasteia uma bandeira, a levantada da bandeira, com a imagem de um santo, a qual é acompanhada de uma grande festa, com cantigas de roda, Folia de Reis e, às vezes, quadrilha. Após a levantada da bandeira, passados alguns dias, essa bandeira é roubada sem que ninguém veja ou saiba. A pessoa que levou a bandeira do santo deve escondê-la sem falar para ninguém.

No ano seguinte, o morador que levantou a bandeira prepara sua casa com comidas e fogueira para recebê-la e para descobrir quem a pegou no ano anterior. Nesse ínterim, a pessoa que roubou a bandeira se prepara também para a entrega - antes de tudo, o ladrão envia uma carta anônima para o morador comunicando que vai entregar a bandeira e faz alguns pedidos a ele. O ladrão deixa comidas típicas prontas e convida algumas pessoas para ajudá-lo a entregar a bandeira. Há um preparativo de chegada com queima de fogos, acompanhada da Folia de Reis, e o ladrão esboça um discurso para alguém ler onde confessa ser ele o ladrão. Depois da revelação, a festa continua com danças e muita diversão. Um detalhe importante a ser citado é que, se o morador levantar a bandeira e ninguém a roubar entre três dias, ele retira a bandeira e volta a levantá-la no ano seguinte.

Ao fazer uma pesquisa sobre as origens das festas juninas, percebeu-se que essas festas têm origem portuguesa e o costume foi trazido ao Brasil pelos colonizadores. No Brasil, as festas se reconfiguraram mediante as influências indígenas e africanas.

Além de buscar informações sobre a história da Comunidade e seus aspectos culturais e religiosos, de forma concomitante objetivou-se conhecer e compreender como ocorreu o processo de escolarização na Comunidade Aurora.

Conforme relatado por Roberto, que estudou na década de 1980, essa foi a época de maior sofrimento relacionado às exigências peculiares aos estudos na comunidade. Não havia infraestrutura e formação dos professores adequados e tão somente se ensinava a escrever o próprio nome:

Pesquisador: Qual era o meio de estudo?

Roberto: Não tinha. A gente não tinha escola, tinha uma mulher que sabia mais do que nós. Aí, ensinava nós a ler e assinar, pelo menos, o nome da gente. E pra chegar 
até onde ela morava, eu caminhava duas horas a pé, gado corria atrás de nós! Foi indo... nós parou de estudar porque era muito sofrimento, tanto é que eu só tenho a terceira série ${ }^{6}$... não estudei mais depois dessa época. Aí, depois que eu parei de estudar, aí seu Geraldo trouxe uma professora pra sua casa e ela começou a dar aula pras crianças lá na casa dele, mas ela nem era formada direito. Depois, ele fez um quartinho do lado da casa dele, e [ela] foi dando aula lá um bom tempo. Agora, as crianças de hoje em dia têm oportunidade de estudar e tem preguiça de ir. Ônibus passa nas portas das casas e muitos não querem estudar.

Pesquisador: Hoje na comunidade tem escola?

Roberto: Tem! Na década de 90, eles [o Município] fez o Grupo e até hoje ela ainda tá funcionando... que é para os mais pequenos. Eles estudam até uma certa idade, aí depois eles passa pra Nova Aurora ${ }^{7}$, que fica aqui perto mesmo. Tem o ônibus que passa e leva eles pra lá.

Não havia um espaço definido como escola na época de estudos de Roberto, para o qual tinha que se deslocar por horas até à casa de uma professora leiga, ou seja, sem formação específica em curso de Magistério ou Licenciatura para o exercício da docência. Nota-se a precariedade da educação oferecida à população dessa Comunidade e negligenciada pelo Estado. Com base nesse conhecimento da professora, provavelmente limitado em razão de uma precária escolarização, segundo a fala de Roberto, ele e seus colegas tiveram acesso às primeiras letras e à alfabetização. Somente na década de 1990 a comunidade contaria com uma escola para atender os estudantes dos anos iniciais do Ensino Fundamental.

Nessa narrativa, comprova-se o papel de um importante agente em Aurora: o senhor Geraldo. Ele, que teria participado da fundação oficial da Comunidade na década de 1970, abriu de forma solidária as portas de sua casa para que as crianças continuassem os estudos. Cláudio corrobora a narrativa de Roberto e a complementa com outras informações:

Pesquisador: $O$ senhor sabe quando foi criada a primeira escola na Comunidade e por quem?

Cláudio: O senhor Geraldo foi uma pessoa que sempre interessou pela comunidade. Foi ele que trouxe a primeira professora para a comunidade, com o objetivo de alfabetizar as crianças. Foi com esta bondade deste senhor que as crianças da comunidade aprenderam a ler e a escrever. A primeira escola da comunidade foi ele que doou [o terreno]... não era bem uma escola, era parte da sua casa que ele cedia para a professora lecionar. Era um morador muito dedicado e estava a disposição para ajudar a todos e suas condições financeiras era melhor que a dos outros moradores. Hoje, ele não é mais vivo. No dia 06/02/2019, ele faleceu. Essa professora não teve muitas dificuldade para poder aprender a ler e a escrever, pois seu pai a levava para a escola em Rio Pardo. Eles ia a cavalo e foi assim que, o que ela foi aprendendo, foi passando para as outras pessoas. Vinha crianças de todas as comunidade vizinhas estudar aqui na nossa Comunidade, pois era o único local que tinha escola mais perto. Entre o ano de 1990 a 1992 foi que construiu a primeira escola pelo governo e foi construída na propriedade deste senhor. Ele que doou a terra para ser construída a nova escola... e essa escola funciona até nos dias de hoje.

\footnotetext{
${ }^{6}$ Equivalente ao quarto ano do Ensino Fundamental.

${ }^{7}$ O Povoado de Nova Aurora dista 12 quilômetros da Comunidade Aurora.
} 
Constata-se como o processo de escolarização das crianças na Comunidade Aurora iniciou tardiamente e contou com o protagonismo de pessoas preocupadas com a educação, como o senhor Geraldo. Adiante, com o Estado assumindo a gestão da escola, vê-se que não havia nenhuma preocupação em acolher aqueles estudantes:

Pesquisador: E as estruturas destas escolas, como são?

Roberto: Olha, antes era bem ruinzinha... faltava material e... às vezes, os ônibus chegava atrasados, os alunos ficavam sem cadeira, muitas vezes não tinha merenda... era bem difícil mesmo. Mas, de uns dias pra cá, isso melhorou. Os funcionários das escolas tão tendo mais interesse né, com as eleições feitas dentro da escola e com a ajuda dos pais, isso tá mudando. Agora tem merenda direto, tem cadeira o suficiente.

Pode ser percebido que, mesmo com o Estado assumindo a organização e o funcionamento da escola, os estudantes não dispunham das condições mínimas para estudar e aprender os conteúdos escolares com êxito. Como estudar sem cadeiras e sem merenda? Ao que parece, a escola da Comunidade Aurora, sem ao menos dispor de mobiliário para os alunos, não recebia a mesma atenção que as escolas urbanas recebiam e, proporcionalmente, nem os recursos financeiros necessários para a sua manutenção. Diante das condições apresentadas anteriormente, ao que parece, o modelo de educação oferecido às crianças da Comunidade Aurora possui características da Educação Rural.

Por outro lado, Roberto enfatiza o valor da participação da Comunidade no acompanhamento das atividades escolares, afirmando que houve uma melhoria na qualidade do atendimento aos alunos a partir do momento que os pais começaram a auxiliar na escola, talvez como membros do Conselho Escolar e/ou da Associação de Pais e Mestres. Isso mostra o papel do coletivo - elemento crucial nas características da Comunidade - na constituição de uma escola que, efetivamente, venha a atender aos anseios da comunidade do campo.

No decorrer das entrevistas, verificou-se que a Comunidade Aurora tem uma história rica culturalmente e há uma preocupação de seus moradores em resgatar, manter e dar continuidade a tradições culturais e religiosas, transmitidas de geração a geração, como, por exemplo, nas festas organizadas em Aurora, sempre acompanhadas de dedicação e fé. Além disso, nas falas de Roberto e Cláudio evidenciaram-se particularidades atinentes a uma comunidade tradicional, como os modos de ser e viver no território, incluindo suas práticas de produção e a relação de pertencimento que esses sujeitos estabelecem com a terra, com a sua terra (BRANDÃO; BORGES, 2014). Uma marca presente em Aurora é a organização coletiva de seus membros em diferentes momentos e situações, seja nas festas, seja para apoiar a melhoria de qualidade da escola. Apesar dessa riqueza e beleza cultural, evidenciam-se o 
sofrimento e a luta de seu povo - da escravização de negros nos tempos de antigamente à necessidade de migração sazonal para regiões produtoras de café.

\section{CONSIDERAÇÕES FINAIS}

O objetivo deste artigo foi o de socializar os resultados de um trabalho acadêmico produzido no âmbito de duas disciplinas do curso de Licenciatura em Educação do Campo, trabalho esse realizado em Tempo-Comunidade. $\mathrm{O}$ trabalho solicitado visava (re) constituir a história da comunidade Aurora, município de Rio Pardo de Minas-MG, por meio do referencial teórico-metodológico da História Oral, nas vozes de seus sujeitos locais. Para isso, realizaramse entrevistas com dois moradores da referida Comunidade. O roteiro de entrevista elaborado deu enfoque ao histórico de organização da comunidade, levando em apreço os aspectos culturais, religiosos e educacionais. Ressalta-se que as duas primeiras autoras do artigo são moradoras da Comunidade Aurora e justifica-se a escolha de Aurora, dentre outros motivos, pela relação afetiva construída das licenciandas com o território.

Conclui-se que o uso da História Oral permitiu o levantamento de informações sobre a Comunidade Aurora, algumas delas não eram do conhecimento dos autores, e também contribuiu no registro de uma história da Comunidade, uma história contada por quem viveu e vive naquele território.

Apesar de a Comunidade não ser reconhecida como tradicional, é possível afirmar que Aurora possui algumas de suas características. Destaca-se que os três primeiros autores, ao realizarem o trabalho acadêmico, juntamente com a ampliação do estudo em outras disciplinas da LECampo, tomaram contato com certos termos, tais como geraizeiro e povos e comunidades tradicionais, expressões essas desconhecidas antes de ingressarem no curso de graduação. Foi com o curso de Licenciatura em Educação do Campo que se tornou possível a eles o contato com leituras e discussões desdobradas sobre os conceitos de Comunidade, Território e Identidade do Campo, sendo esse um modo de desnaturalizar o olhar sobre as suas práticas produtivas, práticas culturais, enfim, sobre o seu modo de ver e viver no mundo.

Se antes não eram conhecidos os seus aspectos identitários, atualmente há um reconhecimento dos licenciandos como geraizeiros, indivíduos oriundos de uma comunidade tradicional, dando forma a uma questão de identidade cultural autêntica do campo.

Assim, este processo de pesquisa proporcionou - além de conhecer, descrever e narrar uma versão da história da Comunidade Aurora, contada por seus moradores -, implicações formativas para os futuros professores em Educação do Campo, como a relação de 
pertencimento dos licenciandos com o território norte-mineiro e, no âmbito acadêmico, a iniciação à investigação qualitativa, instrumentalizada por entrevistas semiestruturadas e, posteriormente, pela sua transcrição e análise.

Tomar contato com aspectos culturais e identitários de moradores da Comunidade Aurora provocou os futuros professores a refletir sobre a construção de um modelo de escola do campo que deixe de invisibilizar a história, a cultura e as tradições de seu povo. Os elementos da cultura e as marcas da identidade dos que moram em uma comunidade, se levados ao contexto escolar, tornam possível estabelecer relações entre saberes locais e saberes escolares institucionalizados, além de questionar e problematizar, inclusive, as dimensões social, política e econômica vivida por eles, como a migração sazonal.

Para o docente responsável, houve um continuum entre o momento de discussões e debates na disciplina Seminário Integrador I e a efetivação das atividades em TempoComunidade, na disciplina Espaços Comunitários, Territórios e Integração de Saberes I, extrapolando as expectativas para estudantes ingressantes de um curso de graduação. Experiências como essa mostram a potencialidade formativa do Regime de Alternância, que organiza os tempos e espaços formativos dos cursos de Licenciatura em Educação do Campo, explorando a experiência em comunidade e os conhecimentos denominados tradicionais como parte da formação do futuro professor em Educação do Campo.

\section{REFERÊNCIAS}

ARROYO, Miguel González. Políticas de formação de educadores (as) do campo. Cad. Cedes, Campinas, v.27, n.72, p.157-176, 2007. Disponível em: http://www.scielo.br/pdf/ccedes/v27n72/a04v2772.pdf. Acesso: 02 fev. 2020.

BRANDÃO, Carlos Rodrigues; BORGES, Maristela Correa. O lugar da vida: Comunidade e Comunidade Tradicional. Campo-Território: Revista de Geografia Agrária, v. 9, n. 18, p.123, 2014. Disponível em: http://www.seer.ufu.br/index.php/campoterritorio/article/view/27067. Acesso: 03 mar. 2020.

BRITO, Isabel Cristina Barbosa de. Ecologismo dos gerais: conflitos socioambientais e comunidades tradicionais no norte de Minas Gerais. 2013. 269 p. Doutorado (Doutorado em Desenvolvimento Sustentável: Política e Gestão Ambiental) - Centro de Desenvolvimento Sustentável, Universidade de Brasília, Brasília, 2013, p. 15-77.

CRUZ, Valter do Carmo. Povos e comunidades tradicionais. In: CALDART, Roseli Salete et al. (Org.) Dicionário da Educação do Campo. Rio de Janeiro, São Paulo: Escola Politécnica Joaquim Venâncio, Expressão Popular, 2012, p. 594-600. 
ICHIKAWA, Elisa Yoshie; SANTOS, Lucy Woellner. Vozes da História: Contribuições da História Oral à Pesquisa Organizacional. 7. 2003, Atibaia. Anais... EnANPAD, 2003, p. 1-16.

LOZANO, Jorge Eduardo Aceves. Prática e estilos de pesquisa na história oral contemporânea. In: AMADO, Janaína; FERREIRA, Marieta de Moraes. (Org.). Usos \& abusos da história oral. 8 ${ }^{\text {a }}$. ed. Rio de Janeiro: Editora FGV, 2006, p. 15-25.

RIBEIRO, Marlene. Educação Rural. In: CALDART, Roseli Salete et al. (Org.) Dicionário da Educação do Campo. Rio de Janeiro, São Paulo: Escola Politécnica Joaquim Venâncio, Expressão Popular, 2012, p. 293-299.

UFTM. Projeto Pedagógico do Curso de Licenciatura em Educação do Campo. Uberaba, 2019. Disponível em: http://www.uftm.edu.br/licenciatura-em-educacao-do-campo. Acesso em: 15 mar. 2020.

Recebido em: 25 de junho de 2020. Aprovado em: 26 de agosto de 2020 . 